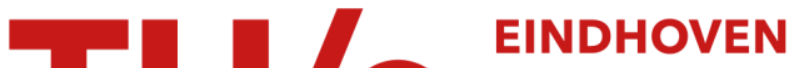 UNIVERSITY OF TECHNOLOGY
}

\section{Components of continuum radiation in an inductively coupled plasma}

\section{Citation for published version (APA):}

Regt, de, J. M., Dijk, van, J., Mullen, van der, J. J. A. M., \& Schram, D. C. (1995). Components of continuum radiation in an inductively coupled plasma. Journal of Physics D: Applied Physics, 28(1), 40-46.

https://doi.org/10.1088/0022-3727\%2F28\%2F1\%2F008, https://doi.org/10.1088/0022-3727/28/1/008

DOI:

10.1088/0022-3727\%2F28\%2F1\%2F008

$10.1088 / 0022-3727 / 28 / 1 / 008$

Document status and date:

Published: 01/01/1995

\section{Document Version:}

Publisher's PDF, also known as Version of Record (includes final page, issue and volume numbers)

\section{Please check the document version of this publication:}

- A submitted manuscript is the version of the article upon submission and before peer-review. There can be important differences between the submitted version and the official published version of record. People interested in the research are advised to contact the author for the final version of the publication, or visit the $\mathrm{DOI}$ to the publisher's website.

- The final author version and the galley proof are versions of the publication after peer review.

- The final published version features the final layout of the paper including the volume, issue and page numbers.

Link to publication

\section{General rights}

Copyright and moral rights for the publications made accessible in the public portal are retained by the authors and/or other copyright owners and it is a condition of accessing publications that users recognise and abide by the legal requirements associated with these rights.

- Users may download and print one copy of any publication from the public portal for the purpose of private study or research.

- You may not further distribute the material or use it for any profit-making activity or commercial gain

- You may freely distribute the URL identifying the publication in the public portal.

If the publication is distributed under the terms of Article 25fa of the Dutch Copyright Act, indicated by the "Taverne" license above, please follow below link for the End User Agreement:

www.tue.nl/taverne

Take down policy

If you believe that this document breaches copyright please contact us at:

openaccess@tue.nl

providing details and we will investigate your claim. 


\title{
Components of continuum radiation in an inductively coupled plasma
}

\author{
J M de Regt, J van Dijk, J A M van der Mullen and D C Schram \\ Department of Physics, Eindhoven University of Technology, PO Box 513, \\ 5600 MB Eindhoven, The Netherlands
}

Received 31 May 1994, in final form 30 August 1994

\begin{abstract}
Measurements of the continuum emission of an inductively coupled plasma in argon have been carried out. The mechanisms responsible for this radiation show different electron-density-dependences. By interrupting the power that is followed by a decay of the electron density, it is possible to unravel these different mechanisms. From the measurements it is concluded that the electron-atom interactions are in general of equal importance to the electron-ion interactions in creating continuum radiation. The relative contribution of the electron-atom interactions depends on the conditions of the plasma. Furthemore, the measurements show that the cross section for electron-atom momentum transfer deduced from our experiment using the formula for electron-atom free-free continuum radiation is not in agreement with the literature.
\end{abstract}

\section{Introduction}

The inductively coupled plasma (ICP) is widely used as a spectrochemical analytical instrument. Knowledge of the fundamental processes can result in better understanding of the ICP and can help to improve its application. In this paper the origin of the continuum radiation in an argon ICP is studied. Three different processes and two different pairs of interacting particles, electron-ion (ei) and electron-atom (ea), are responsible. The three mechanisms are recombination or free-bound interactions ( $\mathrm{fb}$ ) by electron-ion interaction, free-free interactions (ff) between electrons and ions and freefree interactions between electrons and atoms. To estimate the contributions of these different mechanisms, a relatively old technique is used in an improved version $[1,2]$. This method is interruption of the power to an ICP combined with registration of the emission. When the power of the ICP is switched off for about $70 \mu \mathrm{s}$, the continuum radiation changes in intensity. Two processes are relevant for these changes. First, the electrons will cool down to the heavy-particle temperature within a few microseconds. Second, the electron density will decay due to recombination and diffusion. This happens with a time constant of about $200 \mu \mathrm{s}$. This change in the electron temperature $\left(T_{\mathrm{e}}\right)$ followed by that in electron density $\left(n_{\mathrm{e}}\right)$ can be used to distinguish between processes that differ in terms of dependency on electron density or electron temperature. In this paper we will discuss the difference in decay of the continuum contribution created by electron-atom interactions ( $n_{\mathrm{e}}$-dependency) on the one hand and that created by electron-ion interaction $\left(n_{\mathrm{e}} n_{\mathrm{i}}=n_{\mathrm{e}}^{2}\right)$ on the other. Therefore, we will rewrite the contributions to continuum radiation by introducing $\xi$-factors for each of the contributions and measure their relative contribution to the total continuum radiation.

\section{Origins of continuum radiation}

Continuum radiation originates from interaction of free electrons with atoms and ions. If a free electron is captured by an ion then we speak about freebound radiation or recombination radiation. If only the momentum of the electron is changed by the interaction with an atom or ion then the radiation is called free-free radiation. Depending on the pairs of interacting particles, we distinguish between free-free of ei and free-free of ea type. Therefore, the emission coefficient $\varepsilon$ of continuum radiation in a singly ionized gas is given by

$$
\varepsilon_{\mathrm{cont}}=\varepsilon_{\mathfrak{f b}}^{\mathrm{ei}}+\varepsilon_{\mathrm{ff}}^{\mathrm{ei}}+\varepsilon_{\mathfrak{f f}}^{\mathrm{ea}} .
$$

Here $\varepsilon$ is the power emitted per unit of volume, solid angle and wavelength interval, $\varepsilon_{\mathrm{tb}}^{\text {ei }}$ is the continuum emission coefficient due to two-particle recombination, $\varepsilon_{\mathrm{ff}}^{\mathrm{el}}$ the emission coefficient related to free-free interaction between an electron and an ion and $\varepsilon_{\mathrm{ff}}^{\mathrm{ea}}$ is related to the electron-atom interaction. The essence of the experimental technique as presented in this study is that the emission created by ei interaction depends on the product of $n_{\mathrm{e}} n_{\mathrm{i}}$, whereas $\varepsilon_{\mathrm{ff}}^{\text {ea }}$ scales with $n_{\mathrm{e}} n_{\mathrm{a}}$. In an $n_{\mathrm{e}}$-decaying plasma it is possible to unravel the ei and ea contributions from each other. Since 


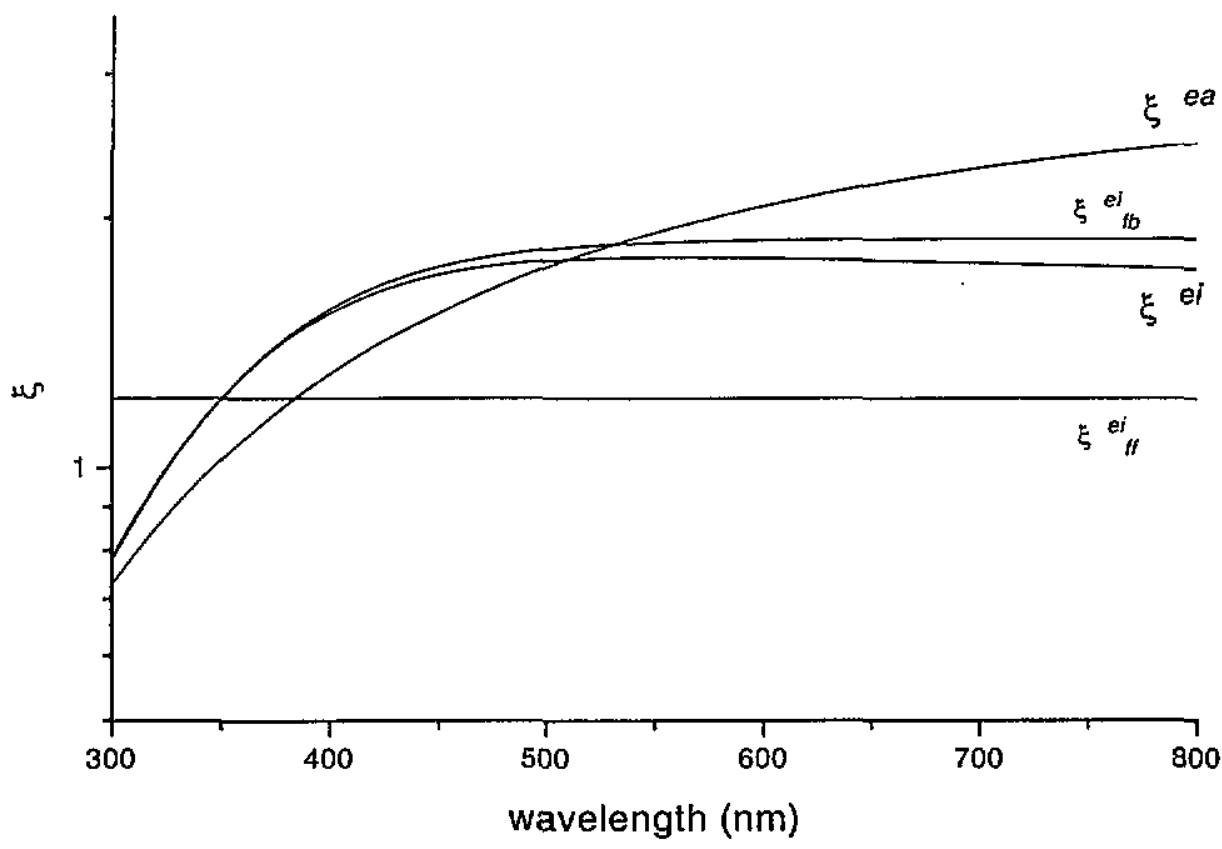

Figure 1. Continuum Biberman factors for $T_{\theta}=12000 \mathrm{~K}$ and $\alpha=0.25 \%$, separately and combined.

$n_{\mathrm{e}}=n_{\mathrm{i}}$ in a singly ionized, quasi-neutral plasma the total continuum emission can be written as

$$
\varepsilon_{\text {cont }}=n_{\mathrm{e}}^{2} f\left(\lambda, T_{\mathrm{e}}\right)+n_{\mathrm{e}} n_{\mathrm{a}} g\left(\lambda, T_{\mathrm{e}}\right)
$$

where $f\left(\lambda, T_{\mathrm{e}}\right)=\left(\varepsilon_{\mathrm{ff}}^{\mathrm{ei}}+\varepsilon_{\mathrm{fb}}^{\mathrm{ej}}\right) n_{\mathrm{e}}^{-2}$ and $g\left(\lambda, T_{\mathrm{e}}\right)=\varepsilon_{\mathrm{ff}}^{\mathrm{ea}} / n_{\mathrm{e}} n_{\mathrm{a}}$ are functions of $\gamma_{\mathrm{e}}$ and the wavelength of emission, $\lambda$.

For quantitative approximation of $\varepsilon_{\mathrm{fb}}^{\mathrm{ei}}, \varepsilon_{\mathrm{ff}}^{\mathrm{ej}}$ and $\varepsilon_{\mathrm{ff}}^{\mathrm{ea}}$, we can use the expressions given by Cabannes et al [3]:

$$
\begin{aligned}
\varepsilon_{\mathrm{fb}}^{\mathrm{ei}}=C_{1} \frac{n_{\mathrm{e}} n_{\mathrm{i}}}{\lambda^{2} \sqrt{T_{\mathrm{e}}}}\left[1-\exp \left(\frac{-h c}{\lambda k_{\mathrm{B}} T_{\mathrm{e}}}\right)\right] \xi_{\mathrm{fb}}^{\mathrm{ei}}\left(\lambda, T_{\mathrm{e}}\right) \\
\varepsilon_{\mathrm{ff}}^{\mathrm{ei}}=C_{1} \frac{n_{\mathrm{e}} n_{\mathrm{i}}}{\lambda^{2} \sqrt{ } T_{\mathrm{e}}} \exp \left(\frac{-h c}{\lambda k_{\mathrm{B}} T_{\mathrm{e}}}\right) \xi_{\mathrm{ff}}^{\mathrm{ei}}\left(\lambda, T_{\mathrm{e}}\right) \\
\varepsilon_{\mathrm{ff}}^{\mathrm{ea}}=C_{2} \frac{n_{\mathrm{e}} n_{\mathrm{a}}}{\lambda^{2}} T_{\mathrm{e}}^{3 / 2} Q\left(T_{\mathrm{e}}\right)\left[\left(1+\frac{h c}{\lambda k_{\mathrm{B}} T_{\mathrm{e}}}\right)^{2}+1\right] \\
\times \exp \left(\frac{-h c}{\lambda k_{\mathrm{B}} T_{\mathrm{e}}}\right)
\end{aligned}
$$

in which $C_{1}$ and $C_{2}$ are constants respectively equal to $1.632 \times 10^{-43} \mathrm{~J} \mathrm{~m}^{4} \mathrm{~K}^{1 / 2} \mathrm{~s}^{-1} \mathrm{sr}^{-1}$ and $1.026 \times$ $10^{-34} \mathrm{~J} \mathrm{~m}^{2} \mathrm{~K}^{3 / 2} \mathrm{~s}^{-1} \mathrm{sr}^{-1}, \xi_{\mathrm{fb}}^{\mathrm{ej}}$ and $\xi_{\mathrm{ff}}^{\mathrm{ei}}$ the free-bound and free-free Biberman factors for argon and $Q\left(T_{\mathrm{e}}\right)$ the cross section for momentum transfer in electronneutral species interaction [4]. The constants $h, c$ and $k_{\mathrm{B}}$ are respectively Planck's constant, the velocity of light and Boltzmann's constant. It should be noted that ei free-free interactions described by equation (4) are only valid in the short-wavelength limit, that is for $\lambda \ll$ $h c /\left(k_{\mathrm{B}} T_{\mathrm{e}}\right)$ [3]. Our plasma parameters do not completely fulfil this wavelength restriction, but inaccuracies can be neglected since this type of ei interaction makes only a minor contribution to continuum radiation of the studied plasma.
In order to compare the ei and ea continuum contributions we normalize the $\varepsilon$ values with respect to $n_{\mathrm{e}} n_{\mathrm{i}} /\left(\lambda^{2} \sqrt{ } T_{\mathrm{e}}\right)$ by introducing the generalized factor $\xi^{\mathrm{ej}}$ for electron-ion interactions and $\xi^{\text {ea }}$ for electron-atom interactions:

$$
\begin{gathered}
\xi^{\mathrm{ej}}\left(\lambda, T_{\mathrm{e}}\right)=\xi_{\mathrm{ff}}^{\mathrm{ei}} \mathrm{e}^{-u}+\xi_{\mathrm{fb}}^{\mathrm{ej}}\left(1-\mathrm{e}^{-u}\right) \\
\xi^{\mathrm{ea}}\left(\lambda, T_{\mathrm{e}}, \alpha\right)=\frac{C_{2}}{\alpha C_{1}} T_{\mathrm{e}}^{2} Q\left(T_{\mathrm{e}}\right)\left[(1+u)^{2}+1\right] \mathrm{e}^{-u}
\end{gathered}
$$

with $u=h c /\left(\lambda k_{\mathrm{B}} T_{\mathrm{e}}\right)$ and $\alpha=n_{\mathrm{e}} / n_{\mathrm{a}}$ the degree of ionization just after the cooling jump for $n_{\mathrm{a}} \gg n_{\mathrm{e}}$. by

Now the total continuum radiation can be described

$$
\varepsilon_{\text {cont }}=\xi^{\text {total }} \frac{C_{1}}{\lambda^{2}} \frac{n_{\mathrm{e}}^{2}}{\sqrt{ } T_{\mathrm{e}}}
$$

with

$$
\xi^{\text {total }}=\xi^{\mathrm{ei}}\left(\lambda, T_{\mathrm{e}}\right)+\xi^{\mathrm{ea}}\left(\lambda, T_{\mathrm{e}}, \alpha\right) .
$$

In figure 1 the $\xi$ factors as functions of wavelength are depicted for an electron temperature of $12000 \mathrm{~K}$ and a degree of ionization of $0.25 \%$. For $Q\left(T_{\mathrm{e}}\right)$ in $\xi^{\mathrm{en}}$ the value calculated at $12000 \mathrm{~K}$ by Devoto [4] is taken. The experimental values for the Biberman factors $\xi_{\mathrm{fb}}^{\text {ei }}$ and $\xi_{\mathrm{ff}}^{\mathrm{ei}}$ are taken from Wilbers et al [5]. The influence on the results of the inaccuracy $(<10 \%)$ in these data is negligible relative to the data obtained in our experiment.

To estimate the importance of the free-free ea interaction the parameter $\chi\left(\lambda, T_{\mathrm{e}}, \alpha\right)$ is introduced, which is the relative contribution of this $n_{\mathrm{e}}$ dependent process to the total continuum radiation:

$$
\begin{gathered}
\chi\left(\lambda, T_{\mathrm{e}}, \alpha\right)=\frac{g\left(\lambda, T_{\mathrm{e}}\right)}{g\left(\lambda, T_{\mathrm{e}}\right)+\alpha f\left(\lambda, T_{\mathrm{e}}\right)} \\
=\frac{\xi^{\mathrm{ea}}\left(\lambda, T_{\mathrm{e}}, \alpha\right)}{\xi^{\mathrm{ea}}\left(\lambda, T_{\mathrm{e}}, \alpha\right)+\xi^{\mathrm{ei}}\left(\lambda, T_{\mathrm{e}}\right)} .
\end{gathered}
$$




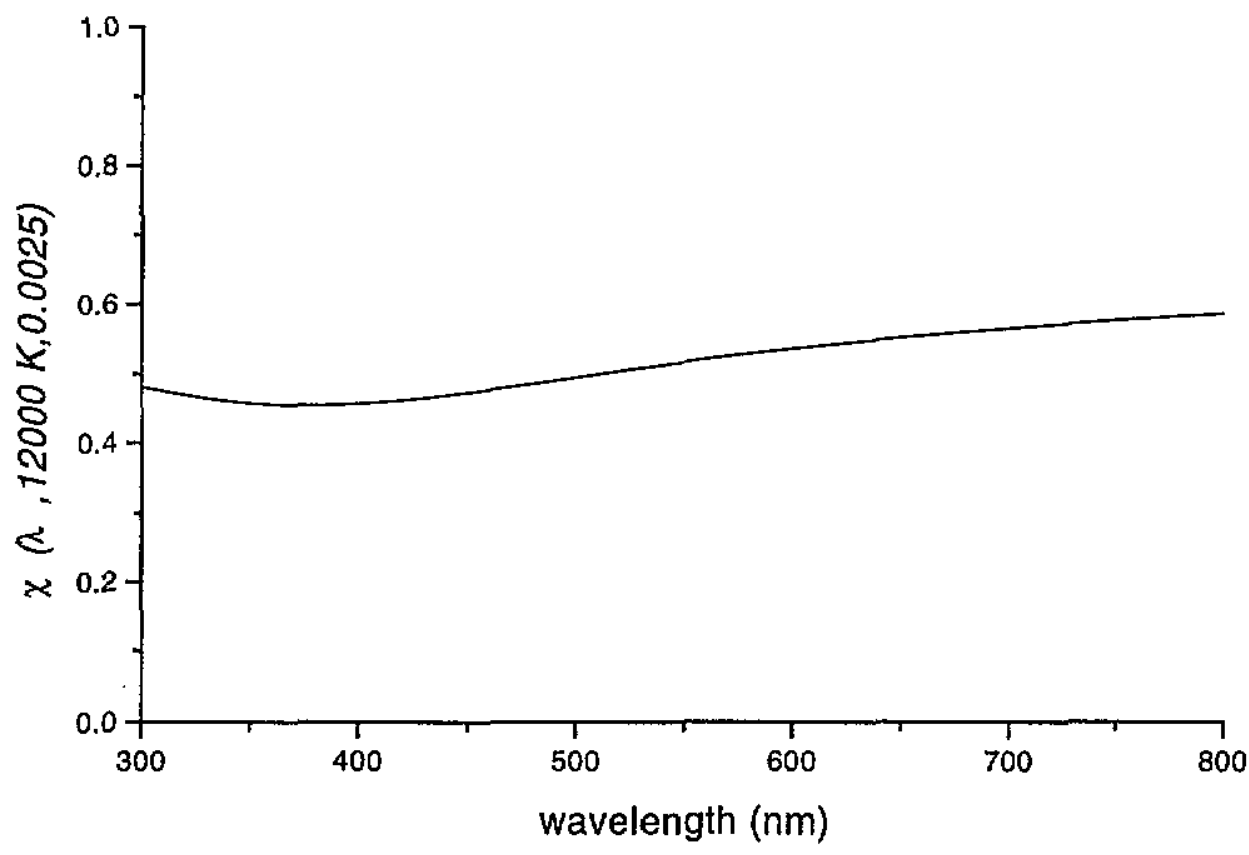

Figure 2. The $\chi$ factor as a function of wavelength for $T_{\mathrm{e}}=12000 \mathrm{~K}$ and $\alpha=0.25 \%$.

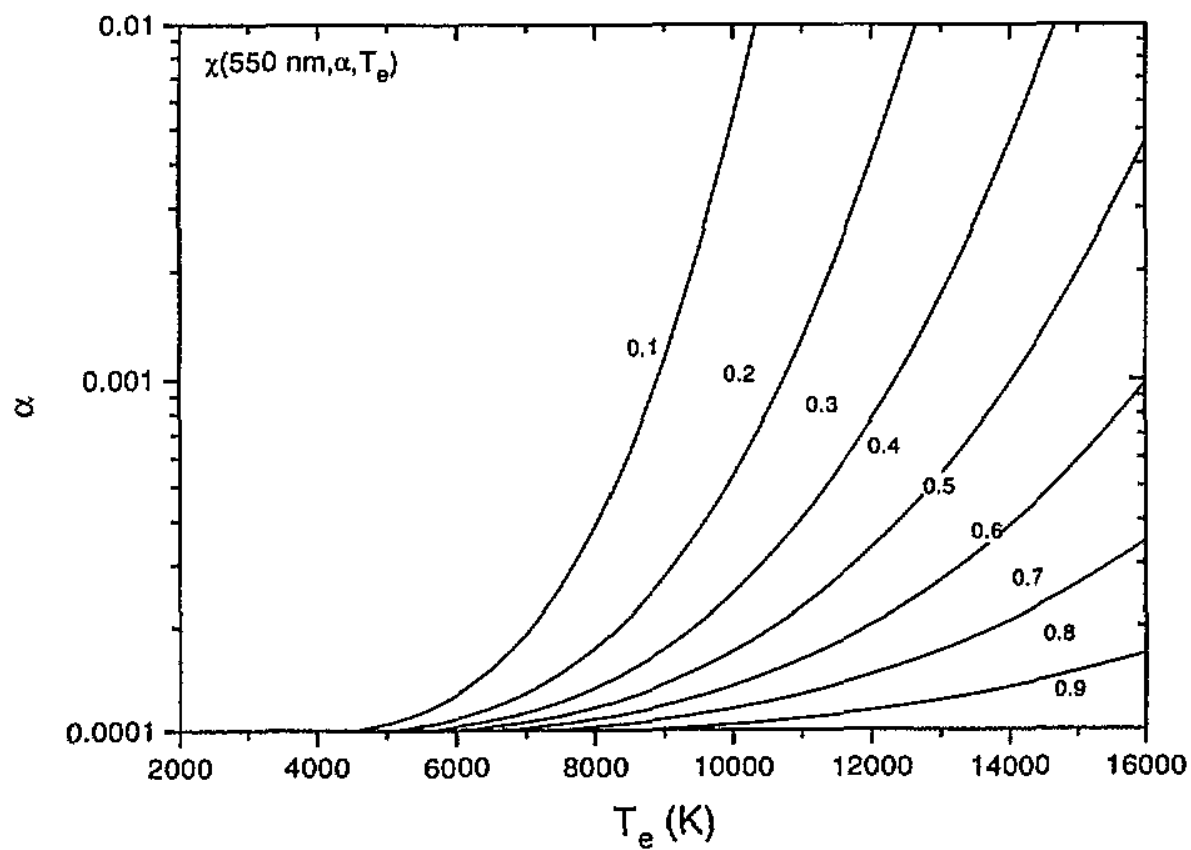

Figure 3. The $\chi$ factors for different degrees of ionization and electron temperatures at $550 \mathrm{~nm}$.

As an example the factor $\chi$ versus wavelength is given in figure 2 for the conditions of figure 1. Note the relatively weak dependence on wavelength. The factor $x$ at $550 \mathrm{~nm}$ is shown in figure 3 as a function of electron temperature and degree of ionization. These were calculated by using equations (6), (7) and (10). Again, for the electron-atom momentum-transfer cross section the electron-temperature-dependent value of Devoto [4] is used. Note the strong dependence of $\chi$ on the degree of ionization and electron temperature. Except for very small values, $\chi$ depends relatively weakly on the exact value of the Biberman factors $\xi_{\mathrm{ff}}^{\mathrm{el}}$ and $\xi_{\mathrm{fb}}^{\mathrm{ei}}$.

\section{Experiments}

\subsection{Description of the set-up}

The ICP is created in a coil, fed by a $100 \mathrm{MHz}$ RF generator developed by Philips. The RF coil consists of two windings of diameter $35 \mathrm{~mm}$ and height $15 \mathrm{~mm}$. The plasma torch placed in the centre of the coil consists of three concentric quartz tubes (see figure 4). This makes it possible to control the three argon gas flows separately. We discern an outer flow of $121 \mathrm{~min}^{-1}$, an intermediate flow of $0.31 \mathrm{~min}^{-1}$ and a central flow of 


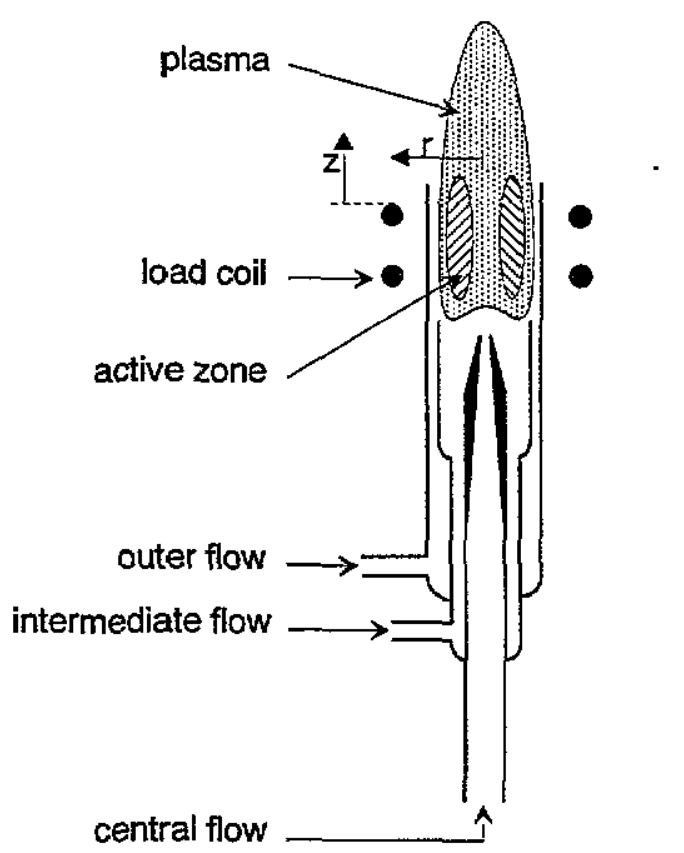

Figure 4. A schematic view of the quartz inductively coupled plasma torch.

$0.61 \mathrm{~min}^{-1}$. The standard operating power is $1.2 \mathrm{~kW}$. It is possible in principle to introduce a nebulized analyte into the plasma, but this is not done in this work. The measurements were carried out on a 'pure' argon plasma. The position at which the measurements were carried out lies about $7 \mathrm{~mm}$ above the load coil and is located just above the hottest area, the skin or active zone of the plasma.

The basic experimental set-up of the power interruption technique is shown in figure 5 . Switching off the generator is performed by a pulse circuit inside the generator, which is controlled by block pulses at TTL level. The off period is chosen to be about $70 \mu \mathrm{s}$. There is a limitation on this off-period since the plasma will extinguish and will not be restarted for long off periods. The plasma is focused on the entrance slit of a I m B\&M BM100 monochromator with a 1200 lines per millimetre grating. The light is detected by a Hamamatsu R376 photomultiplier tube (PMT) operating at $1100 \mathrm{~V}$. The pulses from the PMT are amplified and analysed by a pulse-height discriminator. Then the signal is recorded as a function of time by a multi-channel scaler (MCS). This MCS has 4096 24-bit counters with a minimum integration time of $2 \mu \mathrm{s}$ each. By using this MCS about $8 \mathrm{~ms}$ can be recorded continuously with a resolution of $2 \mu$ s. To obtain a good signal-to-noise ratio from the measurements, the results are the averaged signal over 50000 repetitions.

\subsection{Determining $\chi\left(\lambda, T_{\mathrm{e}}, \alpha\right)$}

To obtain information on the interactions in the plasma, the power interruption (PI) technique is used. For extensive description of the PI technique we refer to Fey et al [2]; here we will give only a global explanation.

The technique is based on the fact that, under standard conditions, energy from the RF coil is

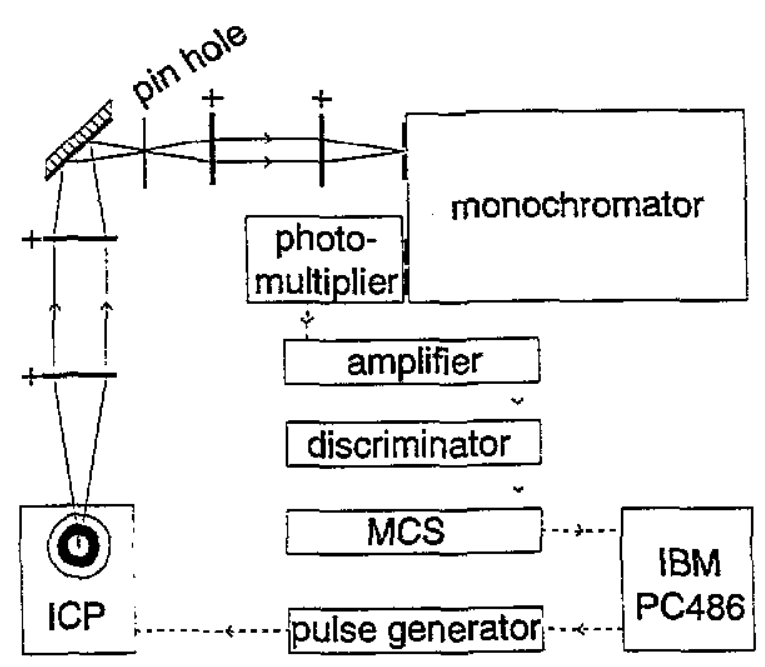

Figure 5. The basic experimental set-up for the emission experiments.

transferred via the electrons to the heavy particles and that, therefore, the electron temperature is higher than the heavy-particle temperature $\left(T_{e}>T_{\mathrm{b}}\right)$. Schematically the energy balance is presented by

$$
\mathrm{RF} \rightarrow\{\mathrm{e}\} \rightarrow\{\mathrm{h}\} \rightarrow \text { surroundings. }
$$

A sudden interruption of the power creates a decay in $T_{\mathrm{e}}$ towards $T_{\mathrm{h}}$ with a typical time scale of $1 \mu \mathrm{s}$, followed by a decay in $n_{\mathrm{e}}$ with a time scale of $100 \mu \mathrm{s}$.

The measured argon levels $\left(\mathrm{Ar}_{\mathrm{p}}\right)$ are close to the ion ground state $\left(\mathrm{Ar}_{1}^{+}\right)$. This makes it true that the populations of these levels are ruled by the Saha balance

$$
\operatorname{Ar}_{\mathrm{p}}+\mathrm{e}+\left(I_{\mathrm{p}}\right) \leftrightarrow \mathrm{Ar}_{1}^{+}+\mathrm{e}+\mathrm{e}
$$

of ionization (to the right) and recombination (to the left). The energy $I_{\mathrm{p}}$ in brackets is the ionization energy needed for electrons to execute the ionization process. Switching off the power supply means that the electrons will cool down to the heavy-particle temperature. This implies that the group of electrons with sufficient translation energy will decrease in number. Owing to the fact that recombination is going on, the balance (11) will shift towards the left. This implies that the density of $\mathrm{Ar}_{\mathrm{p}}$ will increase suddenly. After this so-called cooling jump the density of the argon level will decay due to decay of the electron and ion density $\left(n_{\mathrm{e}}=n_{\mathrm{i}}\right)$. It is assumed that the density of $A r_{p}$ obeys the Saha balance at any time, which predicts that $\operatorname{Ar}_{\mathrm{p}}$ scales with $n_{\mathrm{e}}^{2}$. It is this decay that will be used to unravel the continuum radiation due to ei interactions $\left(n_{\mathrm{e}}^{2}\right)$ from that of the ea type $\left(n_{\mathrm{e}}\right)$. An example of the response of the $6 \mathrm{~d}$ argon line to power interruption is shown in figure 6 .

Measurements of an argon line during interruption provide the time constant related to the decay of $n_{\mathrm{e}}^{2}$ [2]. This time constant Iargely depends on the position and plasma power, so it is necessary to measure it for each condition. If we assume that the electron density as a function of time decays exponentially, then the timedependent continuum emission at a certain wavelength 


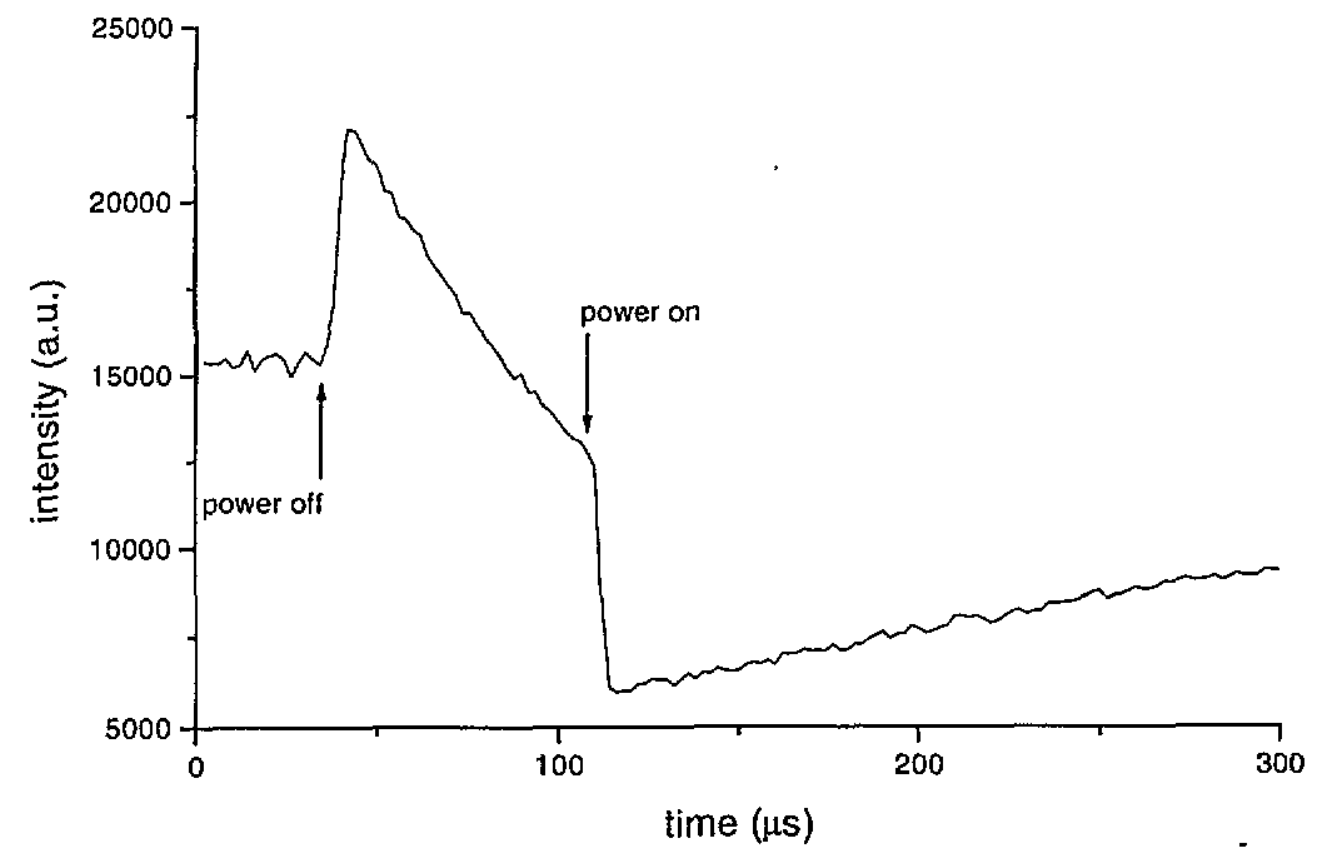

Figure 6. A typical argon line response induced by power interruption.

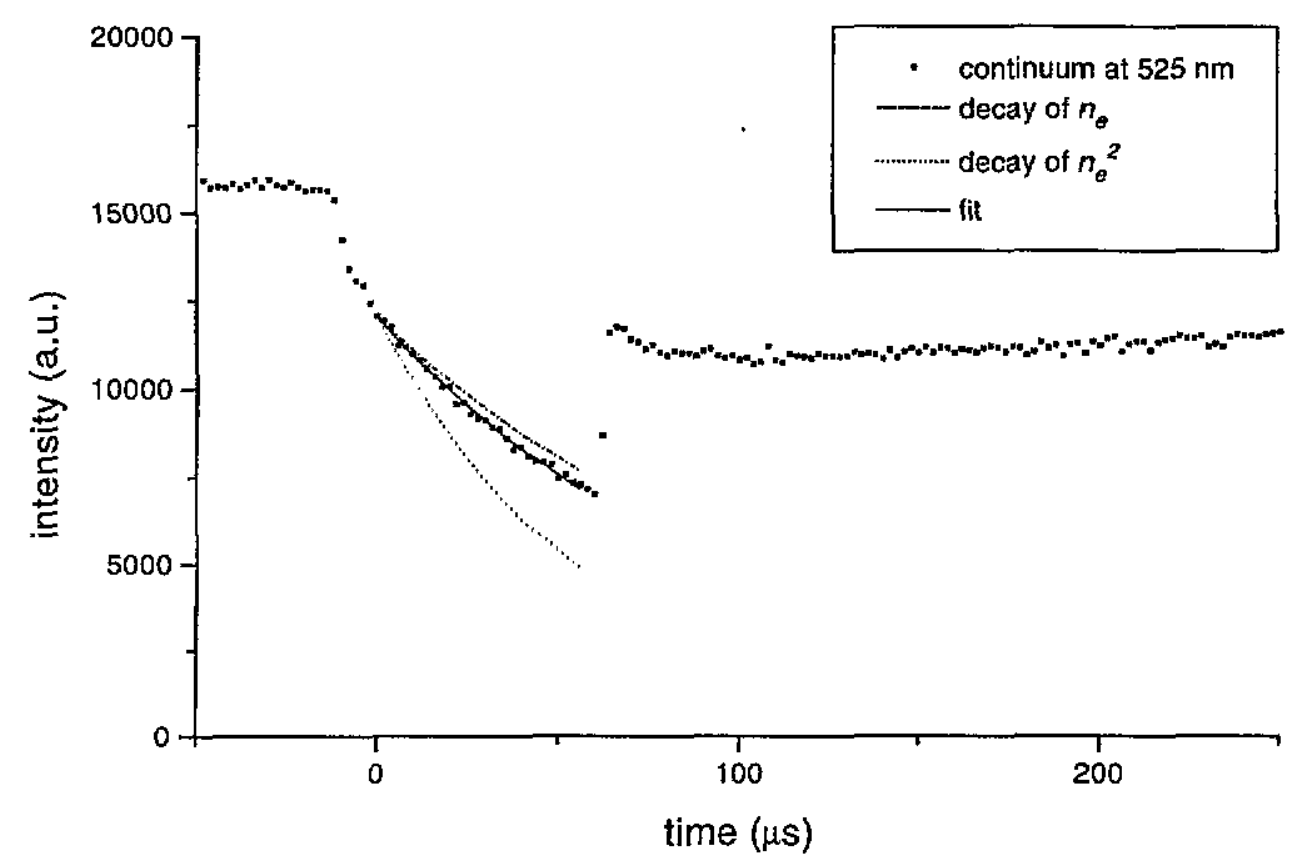

Figure 7. A typical continuum measurement during power interruption at $525 \mathrm{~nm}$.

can be described as

$$
\varepsilon_{\text {cont }}=\varepsilon_{0}\left[\chi\left(\lambda, T_{\mathrm{e}}, \alpha\right) \mathrm{e}^{-t / \tau}+\left(1-\chi\left(\lambda, T_{\mathrm{e}}, \alpha\right)\right) \mathrm{e}^{-2 t / \tau}\right] .
$$

The first term describes the contribution to the continuum of electron-atom interactions $\left(n_{\mathrm{e}}\right.$-dependency) and the second term that of electron-ion interactions $\left(n_{\mathrm{e}}^{2}-\right.$ dependency).

A typical value of $\tau$ is found to be $\tau=200 \mu \mathrm{s}$ (for $P=1.5 \mathrm{~kW}$ ), deduced from the measured decay in intensity of line radiation at the same lateral position. $\varepsilon_{0}$ is the emission coefficient of the continuum radiation at $t=0 \mathrm{~s}$. After switching off the power the electrons cool down to the heavy-particle temperature within $1 \mu \mathrm{s}$ and start to recombine. Since we are only interested in the last process, the fit has to start when the electron temperature becomes more or less stable. This is defined to be $t=0 \mathrm{~s}$, which is usually $12 \mu \mathrm{s}$ after the start of the power interruption.

The response of the continuum to power interruption, induced by decreasing electron density, can be seen in figure 7. The lower and upper lines are respectively the decay described by only the $n_{\mathrm{e}}$-dependent processes or only the $n_{\mathrm{e}}^{2}$-dependent processes. The line in between is the measured and fitted decay (using equation (12)), 


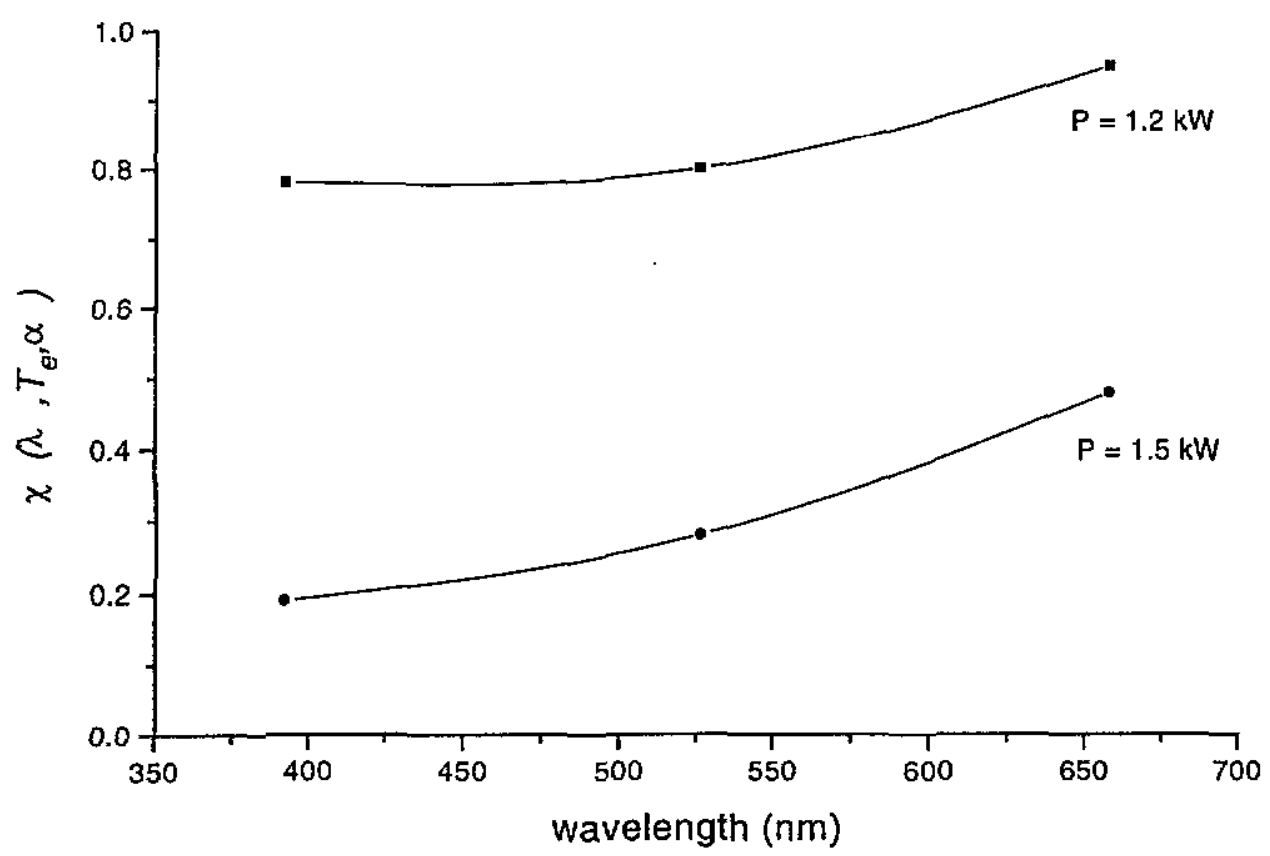

Figure 8. Measured $x$ factors as a function of wavelength for two different input powers. The position is $7 \mathrm{~mm}$ above the load coil and $4.5 \mathrm{~mm}$ from the centre of the plasma torch.

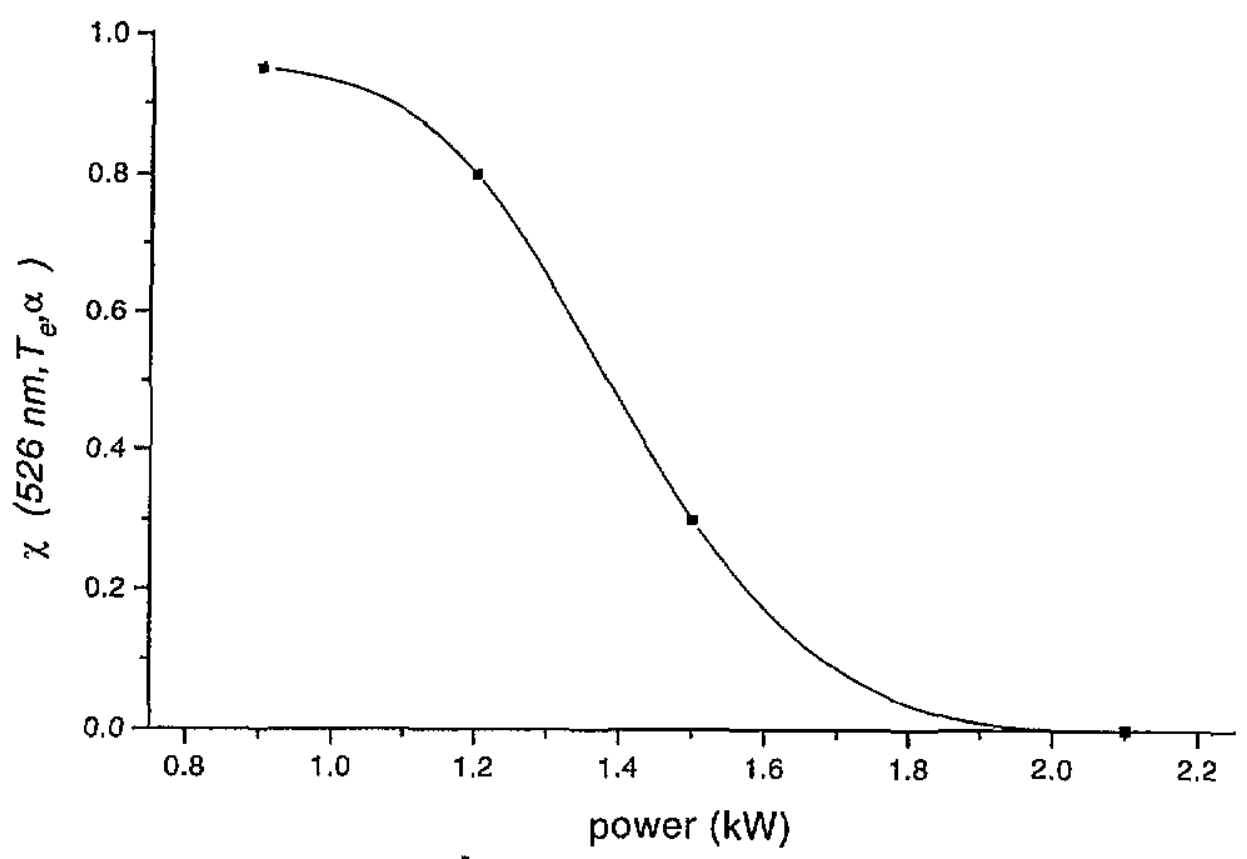

Figure 9. The measured $\chi$ factor as a function of input power at $525 \mathrm{~nm}$. The position is $7 \mathrm{~mm}$ above the load coil and at a radius of $4.5 \mathrm{~mm}$.

a combination of $n_{\mathrm{e}}$ - and $n_{\mathrm{e}}^{2}$-dependent processes. In this way a value of $\chi$, the relative contribution of the $n_{\mathrm{e}}$-dependent part of the continuum, is obtained for each measured wavelength.

\section{Results and discussion}

The initial response to power interruption of the argon line intensity is the opposite to that of the continuum radiation, compare figures 6 and 7 . On switching off the power supply, the line intensity increases whereas the continuum intensity decreases. Therefore, studying the time-resolved emission during interruption of the plasma power gives unequivocal information about the detected radiation, whether it is line or continuum radiation. Hence, this method can be used for tracing continuum radiation.

Now the results of the measured $\chi$ factors, that is, the importance of electron-atom interactions for the 
continuum radiation, will be discussed. All the presented measurements were performed $7 \mathrm{~mm}$ above the load coil and $4.5 \mathrm{~mm}$ from the plasma centre. Using the measured decay time of an argon line as a response to the power interruption, the $\chi$ factor is measured as explained in section 3.2. in figure 8 the experimentally obtained $\chi$ factors are given for two different input powers, as a function of three different wavelengths. The weak dependence on wavelength of the $\chi$ factor was predicted by the theory of section 2 . The difference in $\chi$, that is, the relative contribution of electron-atom interactions to the continuum, for the two plasma powers is large. This large power-dependence is shown more explicitly in figure 9 , which gives the $\chi$ factor measured at wavelength $525 \mathrm{~nm}$ for different plasma powers.

The inaccuracies in measured $\chi$ factors are dominated by the uncertainty in the decay time $\tau$. This inaccuracy in $\tau$ causes an average uncertainty in the $\chi$ factor of about $13 \%$. The reproducibility in measured continuum emission during power interruption is so good that it causes only a slight additional inaccuracy of $2 \%$. Note that the first inaccuracy of $13 \%$ in $\chi$ factor is independent of wavelength. This means that the relative values in figure 8 for a certain power have an inaccuracy of only $2 \%$.

As can be seen from figure 9, the $\chi$ factor is large for low powers. This implies that electron-atom interactions are of major importance at low powers. As the plasma power is increased, the contribution of electronion interactions becomes increasingly important. This is just as expected because higher power will create more electrons and ions. At a power of $2.1 \mathrm{~kW}$, nearly the highest attainable power in the used set-up, the continuum radiation is almost entirely created by electron-ion interactions and electron-atom interactions can be neglected. From these measurements it is very clear that, for a plasma like the atmospheric ICP, driven at powers of order $1 \mathrm{~kW}$, the contributions of electronatom interactions to continuum radiation can certainly not be neglected in further calculations.

From the measured $\chi$ factors it can be concluded that the trend in their behaviour agrees with the theory. The absolute value of $\chi$ can be compared with the calculated values depicted in figure 3 . Here, the value of $\chi$ was displayed in a contour plot as a function of electron temperature and degree of ionization. If these parameters are known from other diagnostics like Thomson scattering [6], then the corresponding $\chi$ can be estimated. This comparison shows a discrepancy in $\chi$. It turns out that the calculated $\chi$ value is much lower than the value obtained from the measurements. This discrepancy cannot be explained by inaccuracies in the measured parameters. As can be seen from formulae (7) and (10), the influence on the $\chi$ factor of the electronatom cross section is significant. The calculations can be made to agree with the theory by taking a larger value of this momentum transfer cross section. This leads to the conclusion that the value for the electron-atom cross section used in equation (5) is about 2.5 times larger than predicted. The reason for the discrepancy is not clear, but might be due to the used approximation for the $\varepsilon$ values, which could lose validity under these plasma conditions, or to differences between the definitions of $Q\left(T_{e}\right)$ by Devoto and by Cabannes et al.

\section{Conclusions}

This paper gives a new procedure for measuring the relative contributions to the continuum of electronion and electron-atom interactions. From these measurements it can be concluded that it is certainly not acceptable to neglect the contributions of electronatom interactions to the continuum under widely used ICP conditions. Furthermore, the discrepancy between measurements and theory of the mechanisms contributing to the continuum is about a factor of 2.5. The experiments show a larger experimental cross section for electron-atom interactions than predicted by theories taken from the literature. Finally, the technique can be used for tracing the continuum, because the initial response to power interruption of the continuum is opposite to that of a line emission.

\section{Acknowledgments}

This work is part of the research programme of the Stichting Technische Wetenschappen (STW), which is financially supported by the Nederlandse Organisatie voor Wetenschappenijik Onderzoek (NWO).

\section{References}

[1] Gurevich D B and Podmoshenskii I V 1963 Opt. Spectrosk. 15319

[2] Fey F H A G, Stoffels W W, van der Multen J A M, van der Sijde B and Schram D C 1991 Instantaneous and delayed responses of line intensities to interruption of the $\mathrm{RF}$ power in an argon inductively coupled plasma Spectrochim. Acta B 46885

[3] Cabannes F, Chapelle J C and Venugopalan M (eds) 1971 Reactions under Plasma Conditions (New York: Wiley)

[4] Devoto R S 1973 Transport coefficients of ionized argon Phys. Fluids 16616

[5] Wilbers A T M, Kroesen G M W, Timmermans $\mathrm{CJ}$ and Schram D C 1991 The continuum emission of an arc plasma $J$. Quant. Spectrosc. Radiat. Transfer 45 ।

[6] de Regt J M, Engeln R A H, de Groote F P J, van der Mullen J A M and Schram D C 1994 Thomson scattering experiments on a $100 \mathrm{MHz}$ inductively coupled plasma calibrated by Raman scattering $R e v$. $S c i$. Instrum. to be published 